\title{
Progress towards Continuous Wave Operation of the SRF EINAC at DESY
}

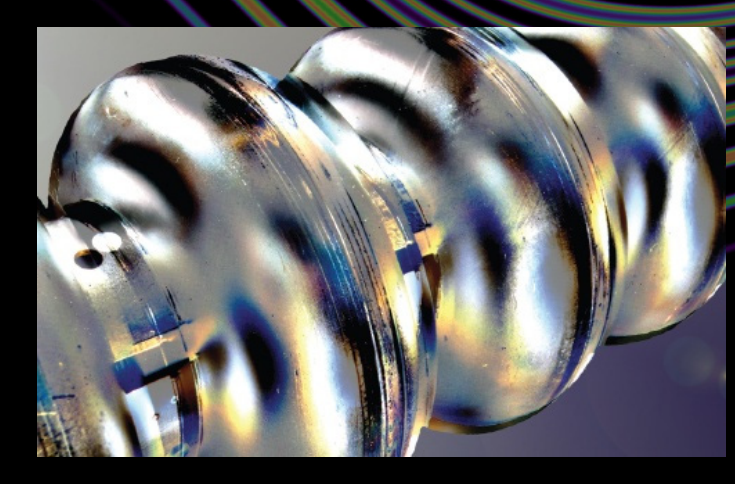

Denis Kostin, Jacek Sekutowicz

Superconductivity \& Particle AcceleratorS, SPAS'2018, IFJ PAN, Krakow, Poland, November $29^{\text {th }} 2018$ 


\section{Outline}

1 Introduction CW SRF

- E-XFEL LINAC

- CW Options and Limits

- CW Operation

- Operating E-XFEL in CW Mode

- CW Summary

2 RF Coupler Issues

- E-XFEL FPC

- CW Modifications

- Coupler R\&D
4 LCLS-II and E-XFEL

- Differences between LCLS-II and E-XFEL

5 LLRF CW operation at CMTB

- CW Module Test

- XM-3 on CMTB

- Pulsed Test Data

- CW Test Summary

\section{Conclusion}

- Summary

\section{Cavity / Cryostat}

- E-XFEL Cavity CW issues 
Introduction CW SRF 


\section{E-XFEL LINAC}

parameters / layout
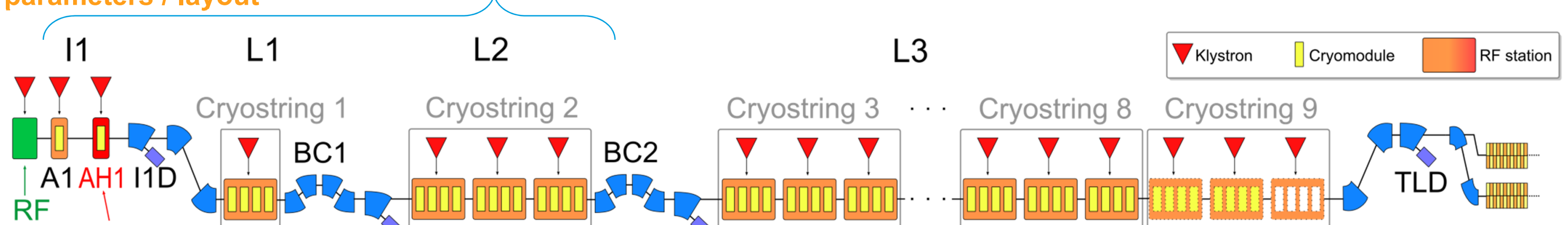

gun $3.9 \mathrm{GHz}$

$\mathrm{DL}$ A2 BC1D $\begin{array}{lllllll}\text { A3 } & \text { A4 A5 } & \text { BC2D A6 A7 A8 }\end{array}$

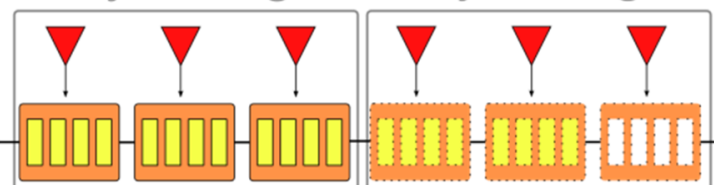
A21 A22 A23 A24 A25 A26 CL

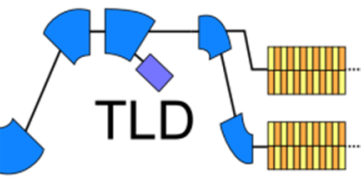

$5 \mathrm{MeV} \quad 130 \mathrm{MeV}$ $700 \mathrm{MeV}$ $2.4 \mathrm{GeV}$ RF Station (4 CM, 10MW klystron) $17.5 \mathrm{GeV}$ Undul. CM1 CM2 $\mathrm{CM} 3$ $\mathrm{CM} 4$

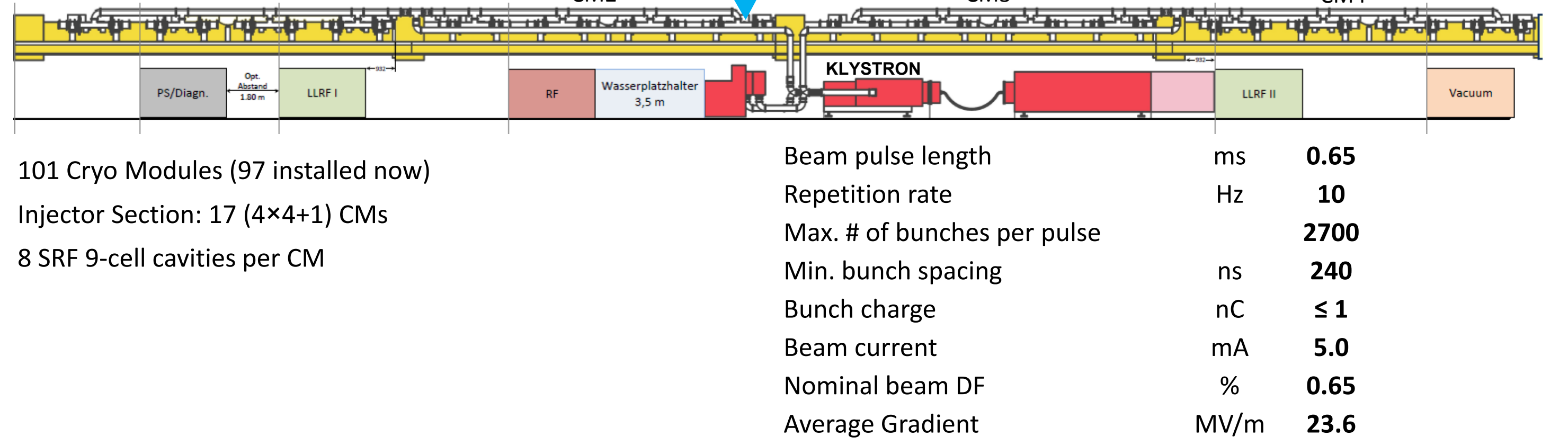




\section{CW Options and Limits}

accelerating module design

2 K, Gas Return Tube

RF power dissipation on the HOM coupler antennae is the main sources of the heat for the end groups

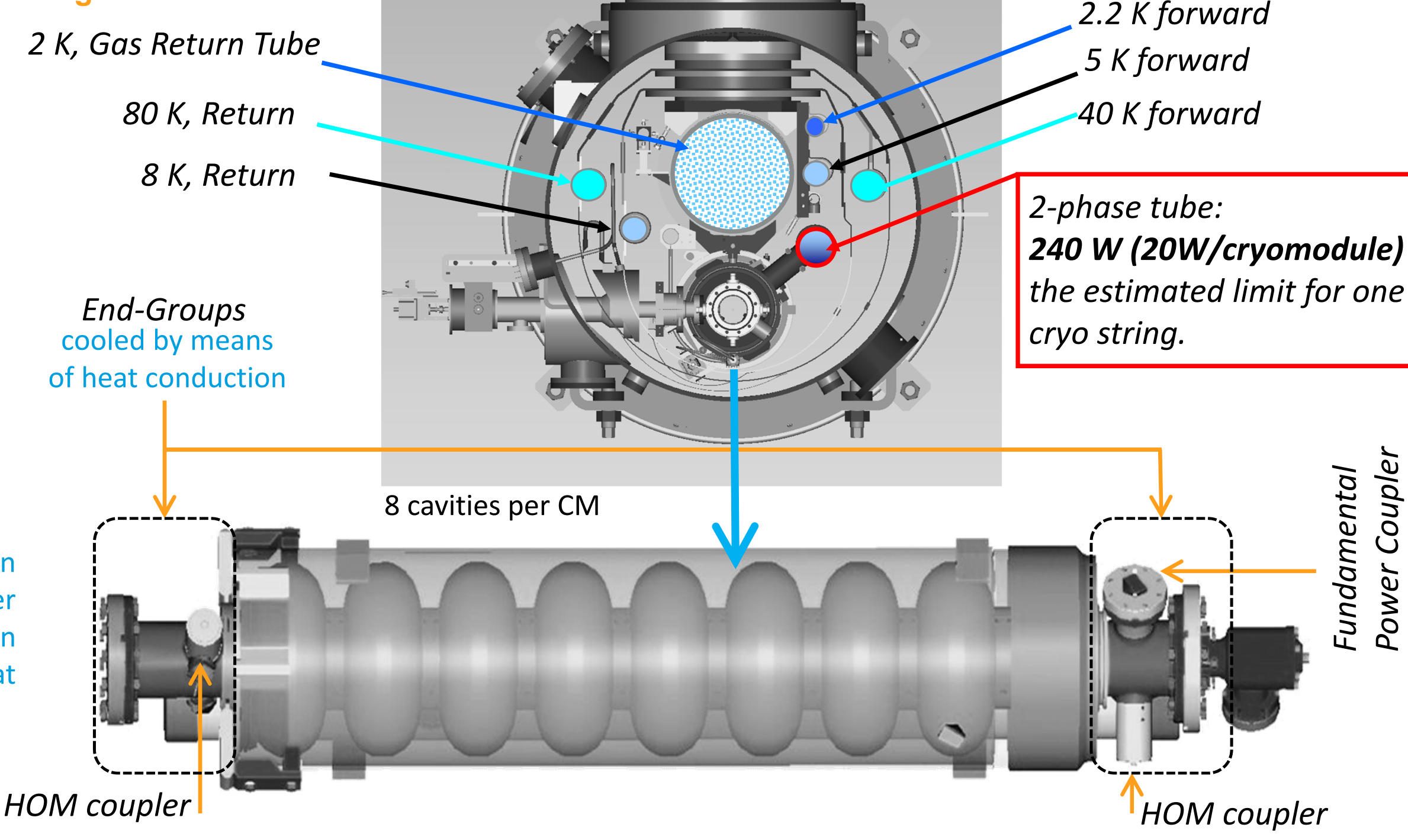




\section{CW Operation}

\section{operating temperature and power}

Operation of LO, L1, L2 and L3 at $2 \mathrm{~K}$

Max. microphonics has been assumed to be peak-to-peak $\pm 15 \mathrm{~Hz}$

\begin{tabular}{|c|c|c|c|c|c|c|c|c|c|c|}
\hline & & at $2 \mathrm{~K}$ & at $2 \mathrm{~K}$ & at $2 \mathrm{~K}$ & at $2 \mathrm{~K}$ & at $2 \mathrm{~K}$ & at $2 \mathrm{~K}$ & at $2 \mathrm{~K}$ & & \\
\hline & & LO & L1 & L2 & L3 CW & L3 LP & $\mathrm{L} 0+\mathrm{L} 1+\mathrm{L} 2$ & L3 & Total CW & Total LP \\
\hline Eacc in LO-L3 & {$[\mathrm{MV} / \mathrm{m}]$} & 20.00 & 20.00 & 20.00 & 7.20 & 12.50 & & & & \\
\hline Total Energy/Linac & {$[\mathrm{GeV}]$} & 0.166 & 0.7 & 2.0 & 5.7 & 10.0 & & & 8.6 & 12.8 \\
\hline$P_{\text {cryo }} / \mathrm{CM}$ & [W] & 194 & 194 & 194 & 20 & 58 & & & & \\
\hline$P_{\text {cryo }} /$ Linac & {$[W]$} & 194 & 777 & 2331 & 1893 & 5590 & 3303 & 1893 & 5196 & \\
\hline 2-phase limit / CM & [W] & new design & new design & new design & 20 & 20 & & & & \\
\hline DF & [\%] & & & & & & 100 & & & 28 \\
\hline
\end{tabular}

Operation of LO, L1, L2 at $1.8 \mathrm{~K}$ and $\mathrm{L} 3$ at $2 \mathrm{~K}$

\begin{tabular}{|c|c|c|c|c|c|c|c|c|c|c|}
\hline & & at $1.8 \mathrm{~K}$ & at $1.8 \mathrm{~K}$ & at $1.8 \mathrm{~K}$ & at $2 K$ & at $2 \mathrm{~K}$ & at $1.8 \mathrm{~K}$ & at $2 \mathrm{~K}$ & & \\
\hline & & LO & L1 & L2 & L3 CW & L3 LP & $\mathrm{L} 0+\mathrm{L} 1+\mathrm{L} 2$ & L3 & Total CW & Total LP \\
\hline Eacc in LO-L3 & {$[\mathrm{MV} / \mathrm{m}]$} & 20.00 & 20.00 & 20.00 & 7.20 & 12.50 & & & & \\
\hline Total Energy/Linac & {$[\mathrm{GeV}]$} & 0.166 & 0.7 & 2.0 & 5.7 & 10.0 & & & 8.6 & 12.8 \\
\hline $\mathrm{P}_{\text {cryo }} / \mathrm{CM}$ & [W] & 119 & 119 & 119 & 20 & 58 & & & & \\
\hline$P_{\text {cryo }} /$ Linac & {$[W]$} & 119 & 474 & 1423 & 1893 & 5590 & 2016 & 1893 & 3909 & \\
\hline 2-phase limit / CM & {$[W]$} & new design & new design & new design & 20 & 20 & & & & \\
\hline DF & [\%] & & & & & & 100 & & & 28 \\
\hline
\end{tabular}




\section{Operating the XFEL in CW}

\section{possible layout}

\section{Injector}

$1.3 \mathrm{GHz}$ module

$3.9 \mathrm{GHz} 3^{\text {rd }}$ harm.
L1

4 modules (1 RF station)
L2

12 modules (3 RF stations)
L3

80 modules

(20 RF stations)

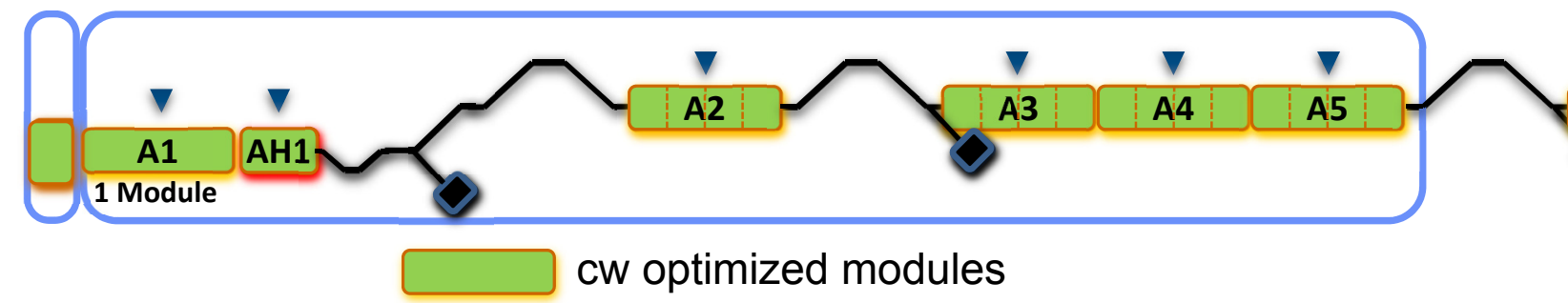

CW optimized modules

1 - Replace the front-end cryomodules (17x)

- Larger cooling capability

- CW optimized cavities

2 - Install CW capable RF sources

- $1 \times$ IOT per RF station

3 - Double the cryo plant (cost driver)

- $2.5 \rightarrow 5 \mathrm{~kW}$

4 - CW electron gun (preferred option: SRF gun)
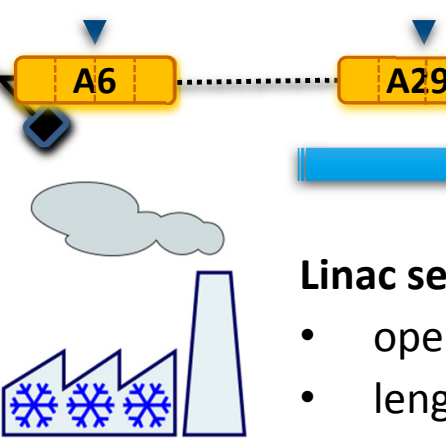

Linac section L3

- operated at moderate CW gradients

- lengthened by former A2 ... A5 $80+12$ modules 24 RF stations Expected energy $8 \mathrm{GeV}$ ! 


\section{CW Summary}

known limits

1. Heat load at $2 \mathrm{~K}$ for each cryomodule must not exceed $20 \mathrm{~W}$ (Limit in $\mathrm{L} 3$ is $20 \mathrm{~W} / \mathrm{CM}$ at $2 \mathrm{~K}$ and $10 \mathrm{~W} / \mathrm{CM}$ at $1.8 \mathrm{~K}$ );

2. Assumed average static load at $2 \mathrm{~K}(1.8 \mathrm{~K})$ is $5 \mathrm{~W} / \mathrm{CM}$;

3. Heating of the HOM couplers must not lead to quenching of the end-cells;

4. The main XFEL linac will not be rebuilt for the new operation modes;

5. An upgrade of the cryogenic plant should be "doable";

6. New RF-sources will be added to the klystrons used for the nominal operation - the new sources should fit in the tunnel: a single RF-source per CM;

7. Bunch quality as high as for the nominal short pulse operation;

8. Gradient in the injector sections is $20 \mathrm{MV} / \mathrm{m}$ for all 136 cavities (may still change - R\&D ongoing).

CW beam:

$25 \mu \mathrm{A}(100 \mathrm{pC}$ and $250 \mathrm{kHz})$

Before upgrade:

$101 \mathrm{CMs}$ in total, 17 in the IS and 84 in L3

After upgrade:

New 17 CMs modified for CW will be installed in the IS

$113 \mathrm{CMs}$ in total, 17 in the IS and 96 in L3

12 present CMs from the IS will be re-installed at the end of L3

Capacity of present cryo-plant is $\sim 2.4 \mathrm{~kW}$.

We will need additional one for the IS 
RF Coupler Issues 


\section{E-XFEL Fundamental Power Coupler}

\section{design and main parameters}

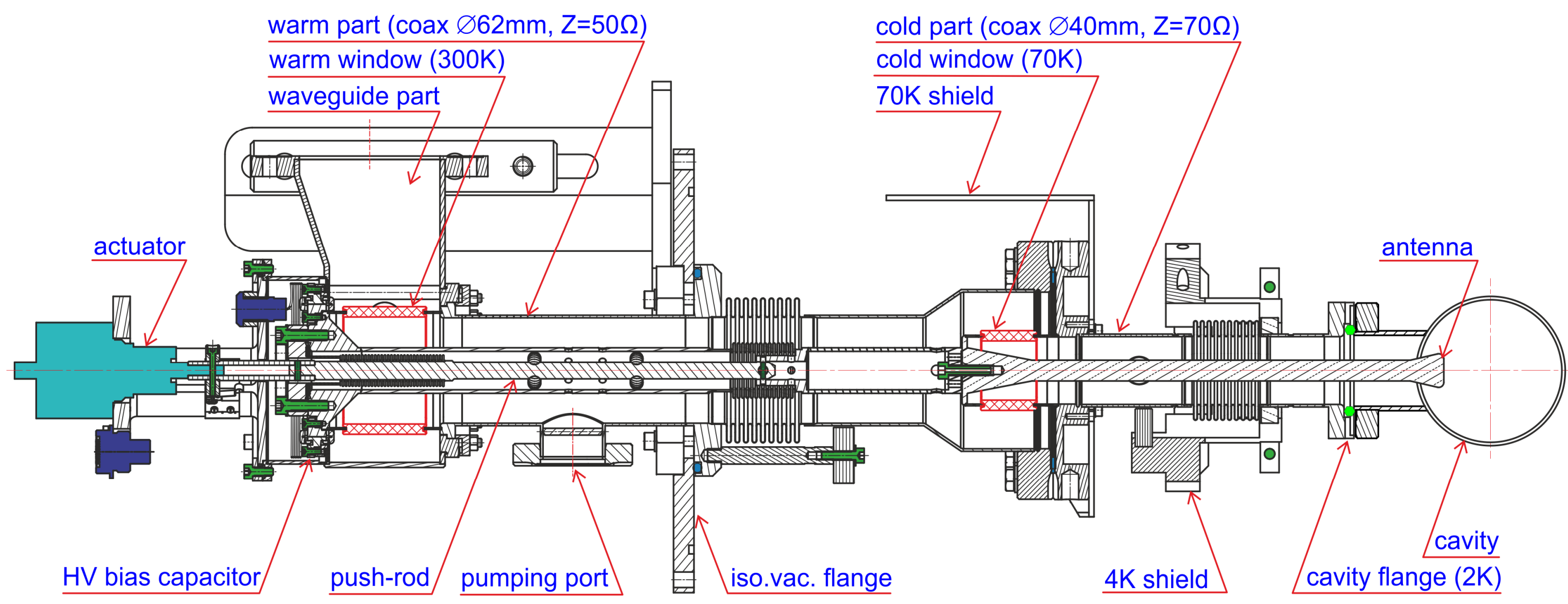

E-XFEL Input RF power coupler consists of warm, cold and waveguide main parts. Coaxial coupler is made of copper and copper plated $(10 / 30 \mu \mathrm{m})$ stainless steel with alumina TiN coated ceramic windows. Motorized antenna tuning $( \pm 10 \mathrm{~mm})$ allows for $\mathrm{Q}_{\text {ext }}$ adjustment $\left(10^{6} . .10^{7}\right)$. 


\section{CW Modifications [1]}

Warm Part shift to achieve higher Qload
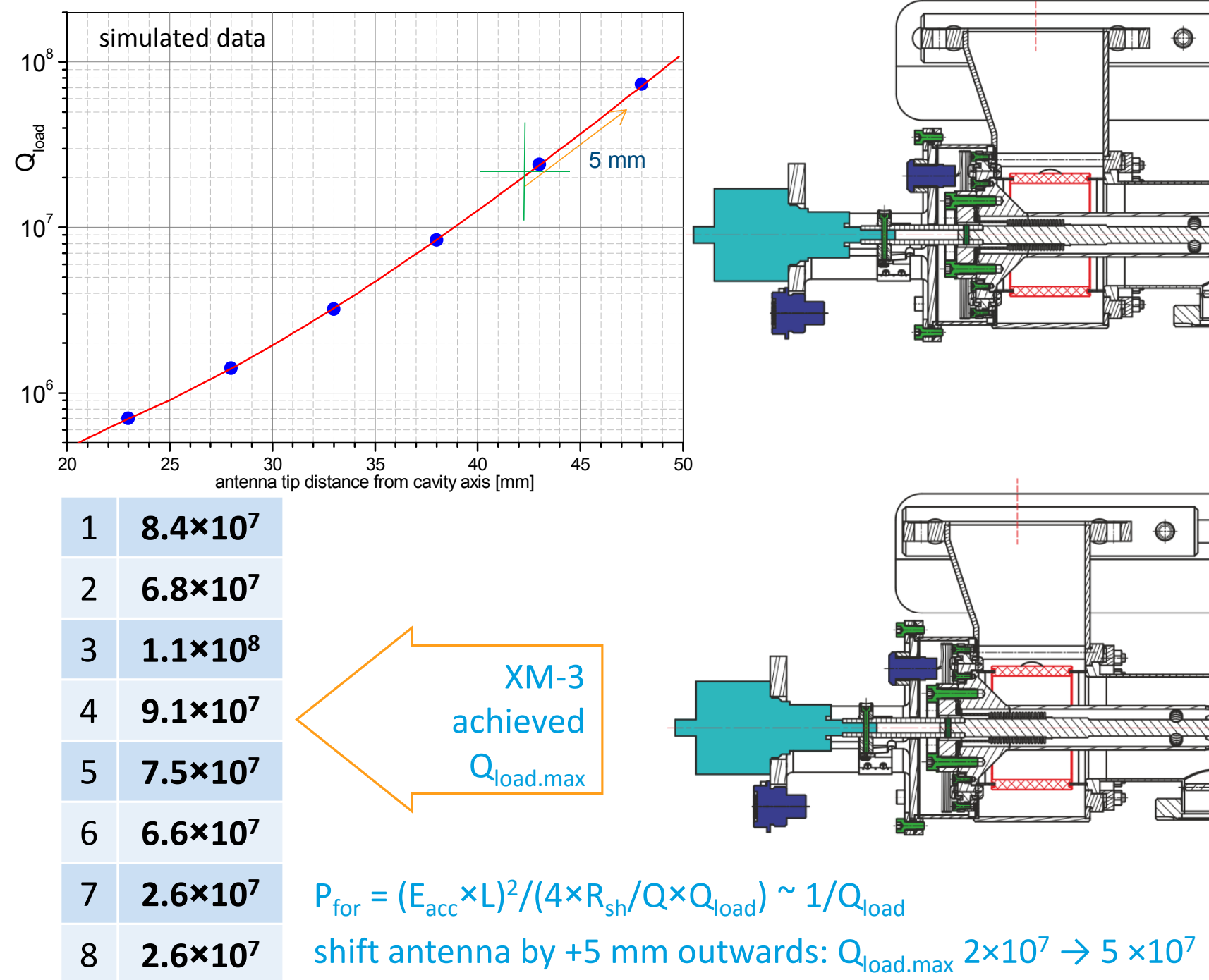


\section{CW Modifications [2]}

\section{Copper Plating with increased average RF power}

- With the CW RF power in a range of $10 . .15 \mathrm{~kW}$ inner conductor overheating will be an issue, with a maximum temperature on the warm inner conductor bellow;

- To decrease the inner conductor temperature it must be gas cooled from inside or copper-plated with increased layer thickness $(\geq 150 \mu \mathrm{m})$ and RRR (>50, 100..160 achieved on last $150 \mu \mathrm{m}$ plating samples);

- Coupler tests with warm parts having $150 \mu \mathrm{m}$ copper re-plated inner conductor are in preparation - 10 warm parts are being re-plated.

plating samples

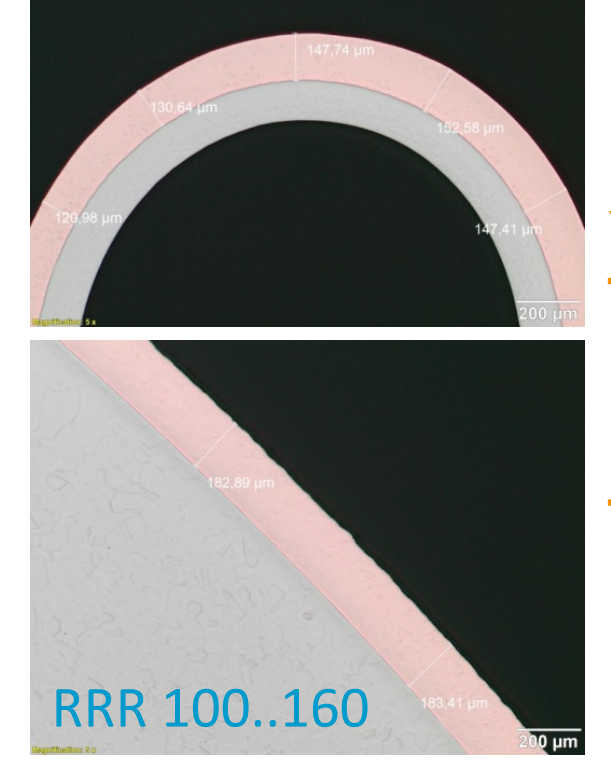

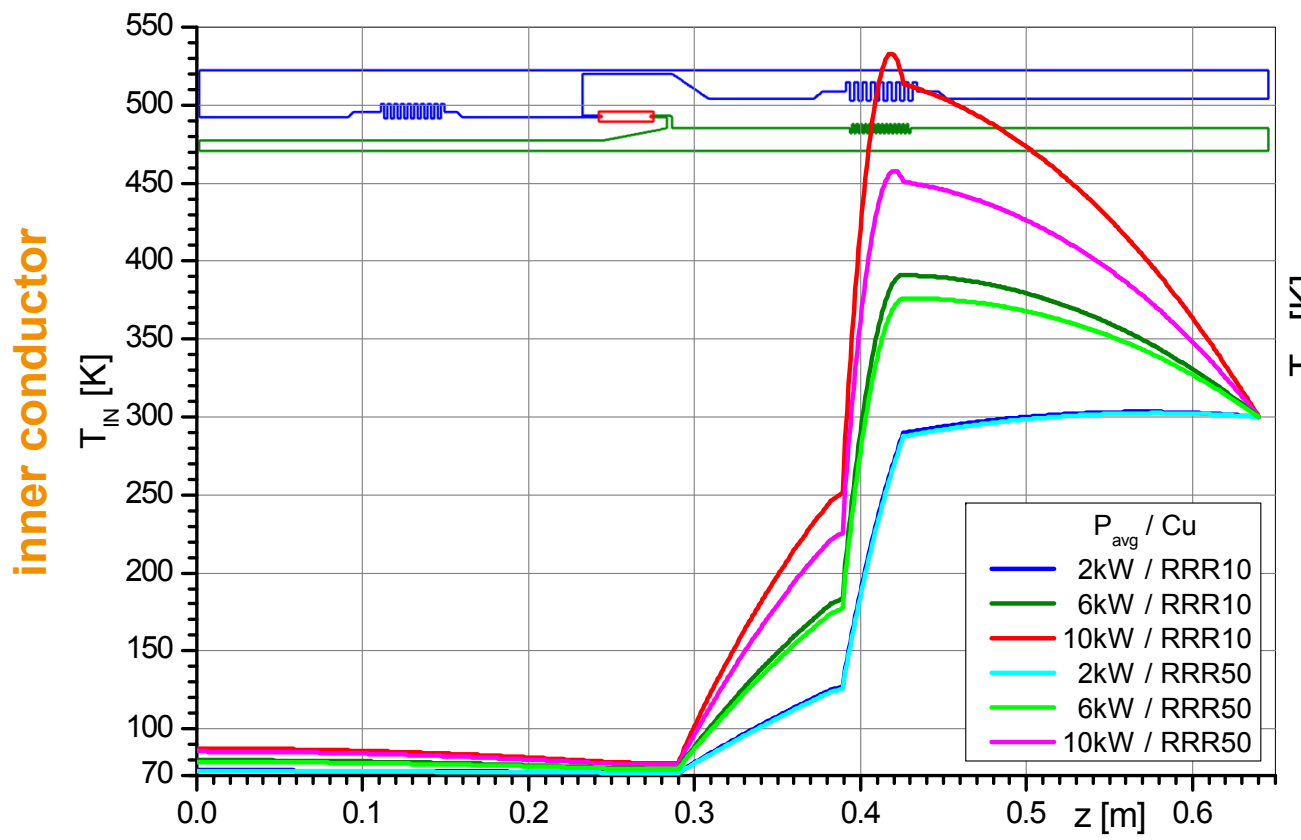

DESY. | Progress towards Continuous Wave Operation of the SRF LINAC at DESY | Denis Kostin, Jacek Sekutowicz, November 29th, 2018
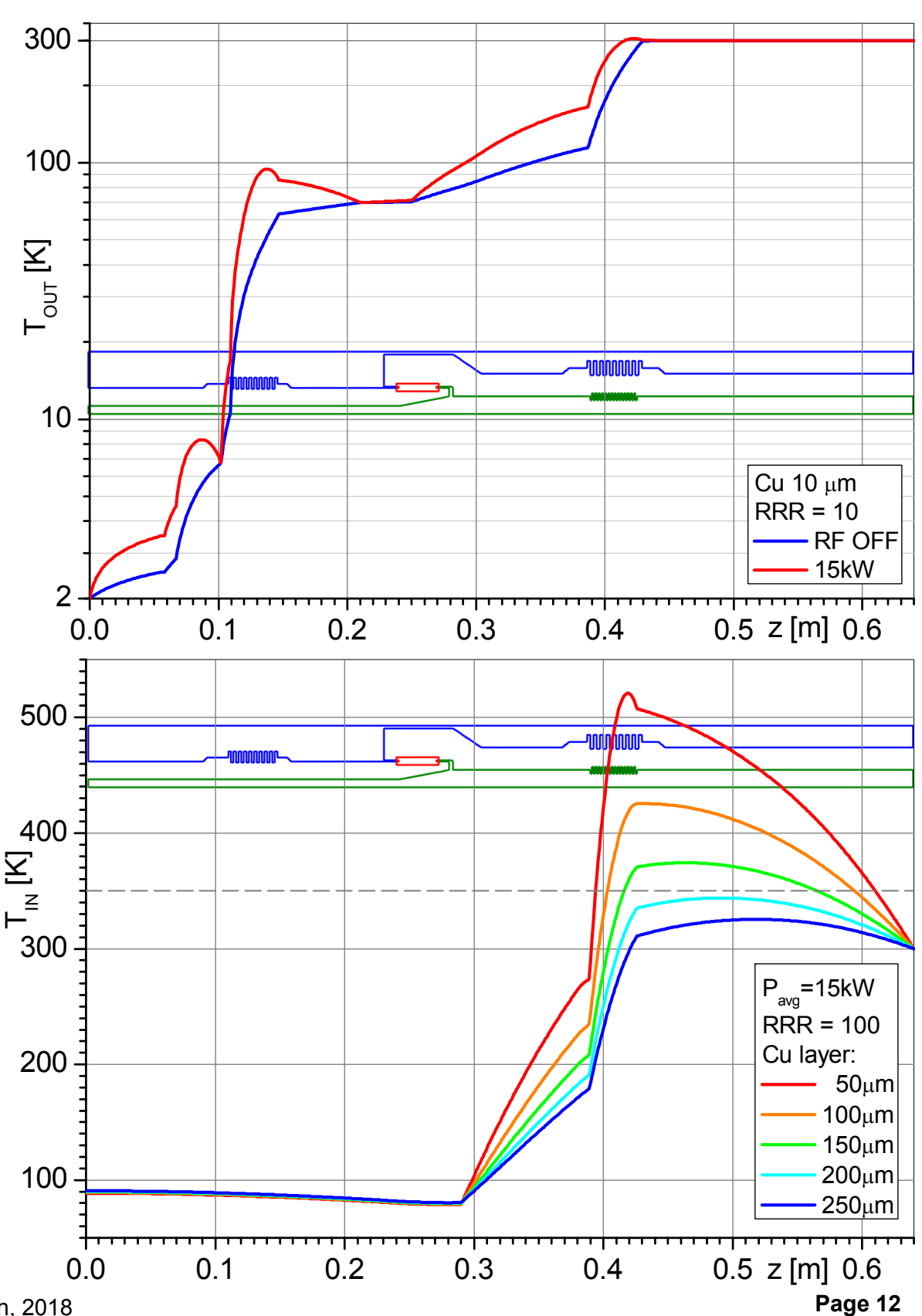


\section{CW SRF Injector Coupler Development}

\section{R\&D program started}

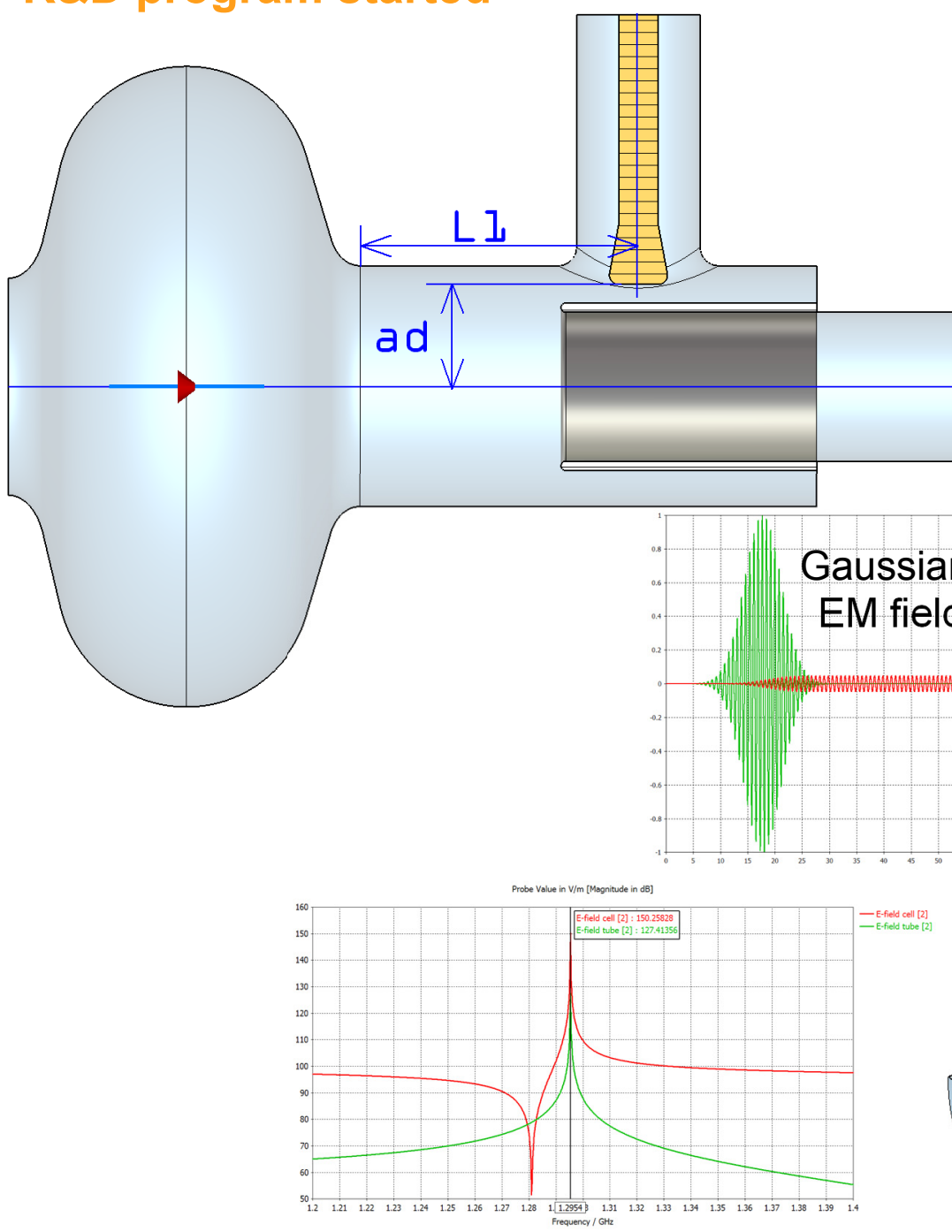

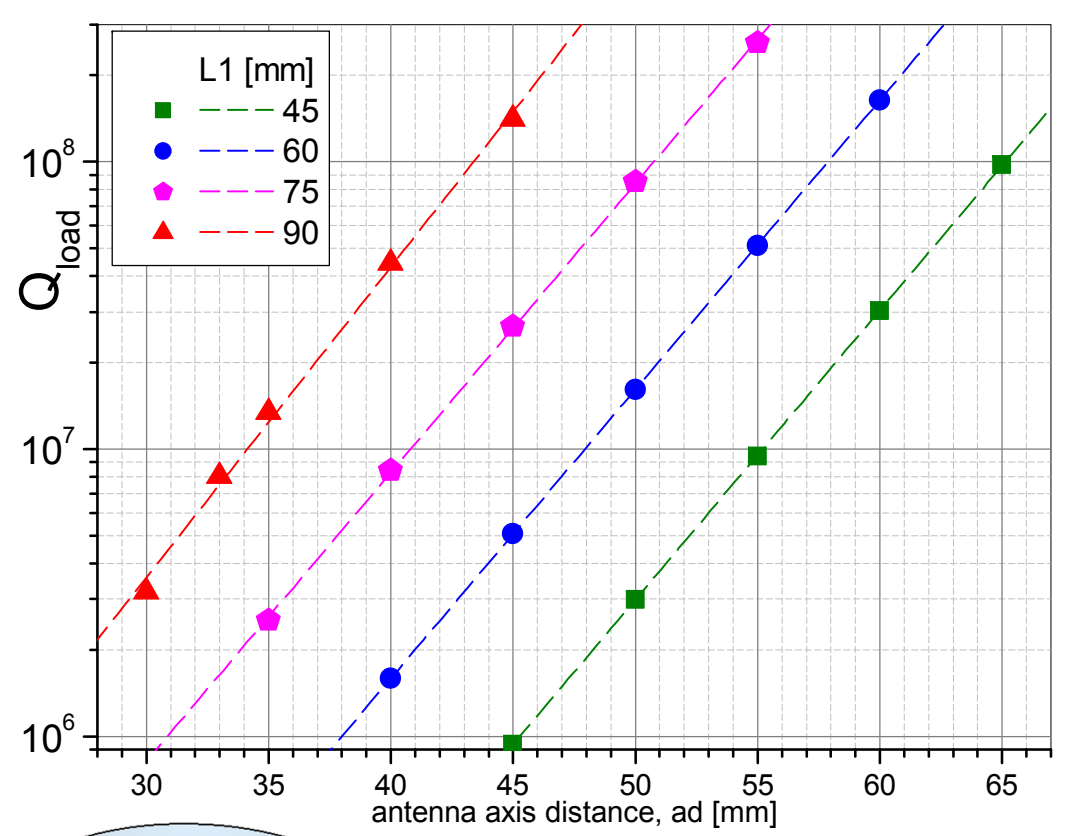

antenna axis distance, ad [mm] 
Cavity / Cryostat 


$$
\text { Pex } x
$$


LCLS-II and E-XFEL 


\section{Differences between LCLS-II and E-XFEL [1]}

\section{LCLS-II design parameters}

$4 \mathrm{GeV}$ up to $300 \mu \mathrm{A}$ CW SRF linac based on TESLA / ILC / E-XFEL $1.3 \mathrm{GHz}$ technology with $110 \mathrm{~W}$ at $2 \mathrm{~K}$ per CM (or better) based on high- $\mathrm{Q}_{0}$ cavity.
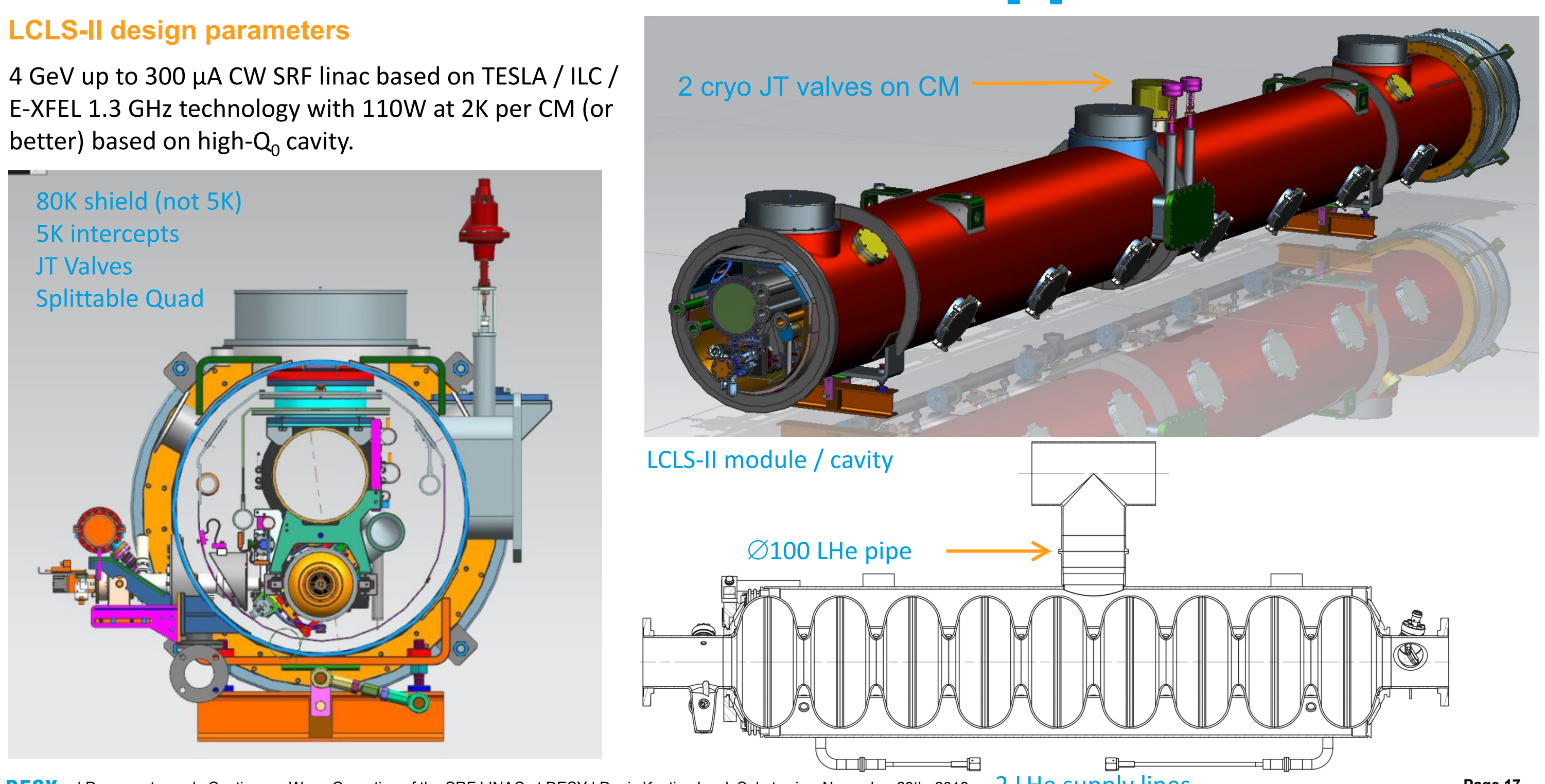


\section{Differences between LCLS-II and E-XFEL [2]}

\section{LCLS-II linac parameters}

\begin{tabular}{|c|c|c|}
\hline component & count & parameters \\
\hline linac & 4 cold segments & $\begin{array}{l}358 \text { cavity Cryomodules }(1.3 \mathrm{GHz}) \\
34 \text { cavity Cryomodules }(3.9 \mathrm{GHz})\end{array}$ \\
\hline 1.3 GHz Cryomodule & 8 cavities / CM & 13 m long. Cavities + SC Magnet package + BPM \\
\hline $1.3 \mathrm{GHz}$ 9-cell cavity & 280 & $\begin{array}{l}\mathrm{E}_{\mathrm{ACC}} \sim 16 \mathrm{MV} / \mathrm{m} ; \mathrm{Q}_{0} \sim 2.7 \times 10^{10}\left(\text { avg) at } 2 \mathrm{~K} ; \mathrm{Q}_{\text {load }} \sim 4 \times 10^{7}\right. \\
\text { bulk niobium fine-grain sheet-metal }\end{array}$ \\
\hline Cavity Auxiliary & per cavity & Coaxial Input Coupler (7kW CW mode); 2 HOM couplers; lever-type cavity tuner \\
\hline Injector & 1 & 1 special cryomodule \\
\hline
\end{tabular}

Close to E-XFEL design, but higher $\mathrm{Q}_{0}$ cavities specified

\section{LCLS-II cryogenics}

\begin{tabular}{|l|c|c|c|}
\hline CM heat loads & $40 \mathrm{~K}$ & $5 \mathrm{~K}$ & $2 \mathrm{~K}$ \\
\hline predicted static heat load per CM [W] & 100 & 12 & 6 \\
\hline predicted dynamic heat load per powered CM [W] & 88 & 10 & 85 \\
\hline predicted total linac heat load [kW] & 9.4 & 0.9 & 3.1 \\
\hline
\end{tabular}

For helium vessel and cryomodule thermal design, a 50\% margin for heat load is taken 


\section{Differences between LCLS-II and E-XFEL [3]}

\section{LCLS-II modifications summary}

1. Origin: the TESLA Type 3+, E-XFEL, and Type 4 designs;

2. Modifications for high heat loads:

- Larger chimney pipe from helium vessel to 2-phase pipe;

- Larger 2-phase pipe (Ø100);

3. Closed-ended 2-phase pipe:

- Separate $2 \mathrm{~K}$ liquid levels in each cryomodule;

- $2 \mathrm{~K} \mathrm{JT}$ valve on each cryomodule;

4. End lever tuner and helium vessel design for minimal df/dP;

5. Two cool-down ports in each helium vessel for uniform cool-down of bimetal joints;

6. No $5 \mathrm{~K}$ thermal shield:

- But retain $5 \mathrm{~K}$ intercepts on input coupler;

7. Input coupler design for $7 \mathrm{~kW}$ CW plus some margin. 
LLRF CW operation

at CMTB 


\section{CW Module Test}

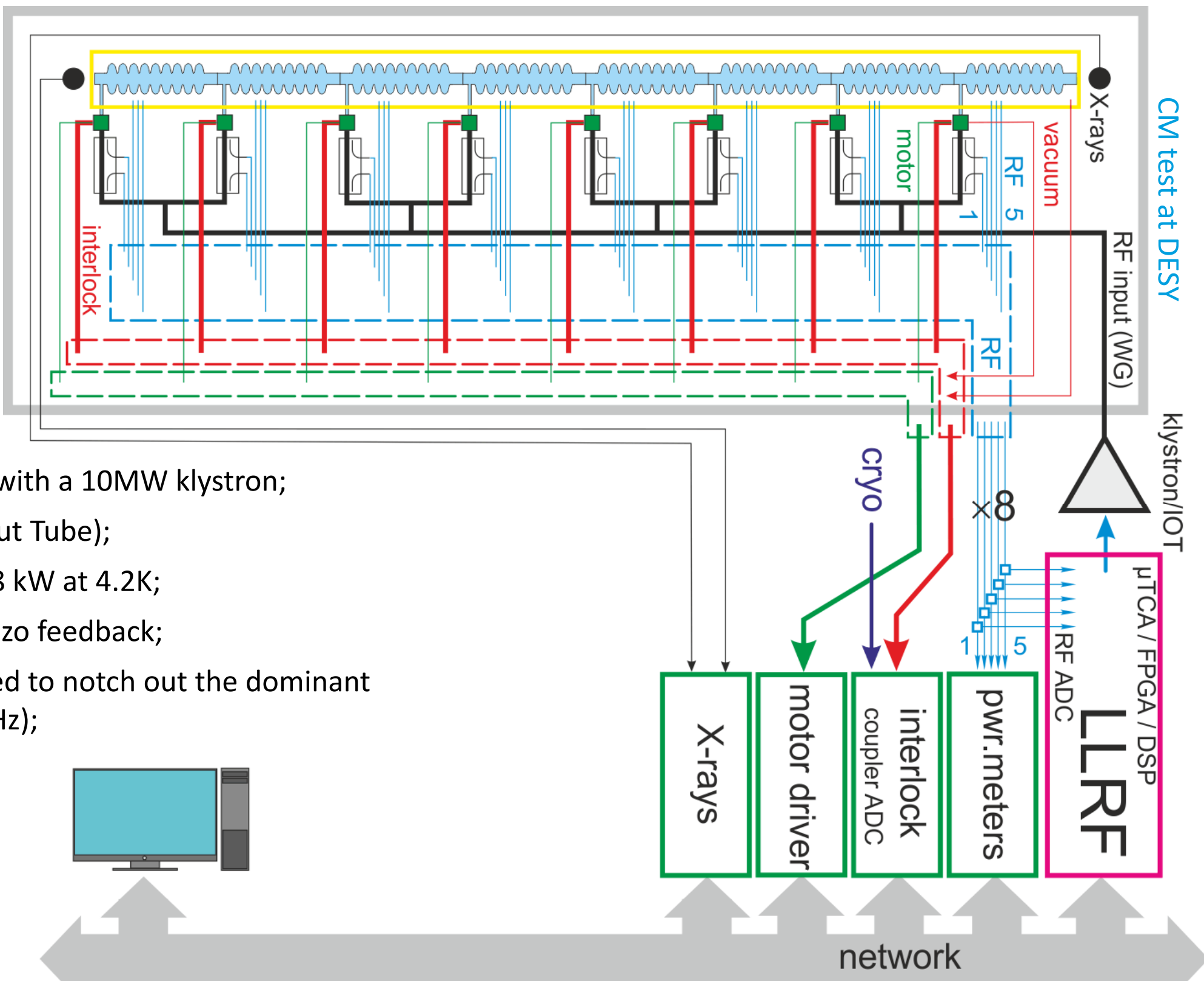

- Standard CMTB pulsed module test is done with a 10MW klystron;

- CW / LP test uses 80kW IOT (Inductive Output Tube);

- CMTB cryoplant has a cooling capacity of $6.8 \mathrm{~kW}$ at $4.2 \mathrm{~K}$;

- CW LLRF system has the RF field and fast piezo feedback;

- Active noise cancellation (ANC) is also applied to notch out the dominant microphonics frequencies (typ. 30 and $49 \mathrm{~Hz}$ );

network 


\section{XM-3 on CMTB}

\section{CW test data}

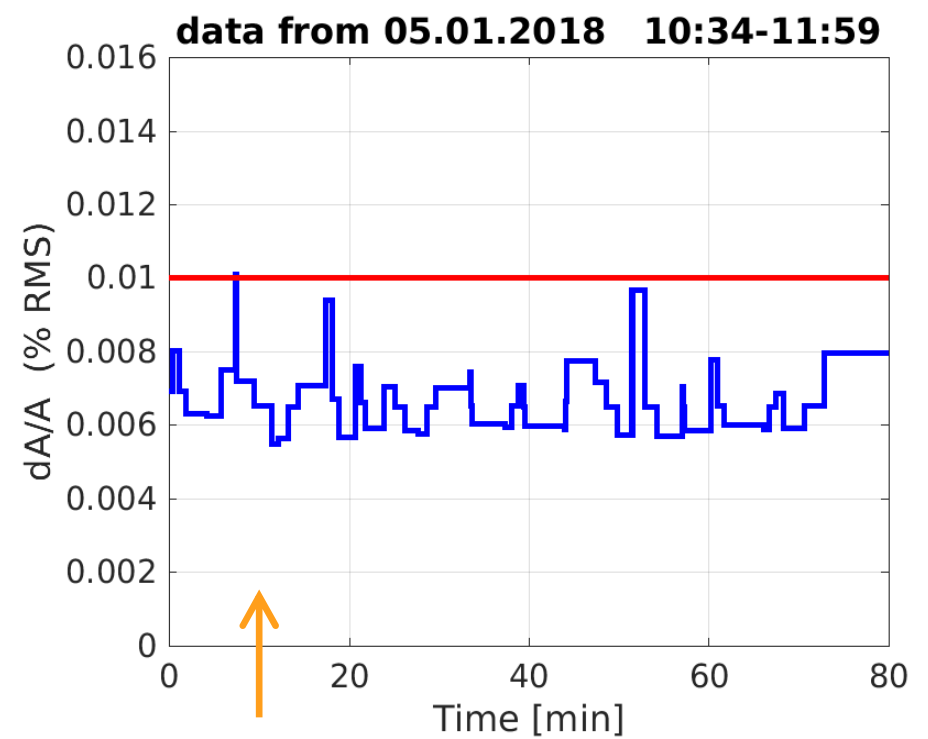

The amplitude and phase regulation level met the XFEL specifications of $0.01 \%$ and $0.01^{\circ}$.

XM-3 individual cavity settings for the VS test

\begin{tabular}{|c|c|c|c|c|c|c|c|c|}
\hline & $\mathrm{C} 1$ & $\mathrm{C} 2$ & $\mathrm{C} 3$ & $\mathrm{C} 4$ & $\mathrm{C} 5$ & $\mathrm{C} 6$ & $\mathrm{C} 7$ & $\mathrm{C} 8$ \\
\hline $\begin{array}{c}\mathrm{E}_{\mathrm{ACC}} \\
{[\mathrm{MV} / \mathrm{m}]}\end{array}$ & 16 & 16 & 8 & 16 & 16 & 16 & 11 & 11 \\
\hline$Q_{L}\left[\times 10^{7}\right]$ & 6 & 6 & 1.4 & 6 & 6 & 6 & 2.5 & 2.5 \\
\hline $\mathrm{BW}[\mathrm{Hz}]$ & 22 & 22 & 93 & 22 & 22 & 22 & 52 & 52 \\
\hline
\end{tabular}
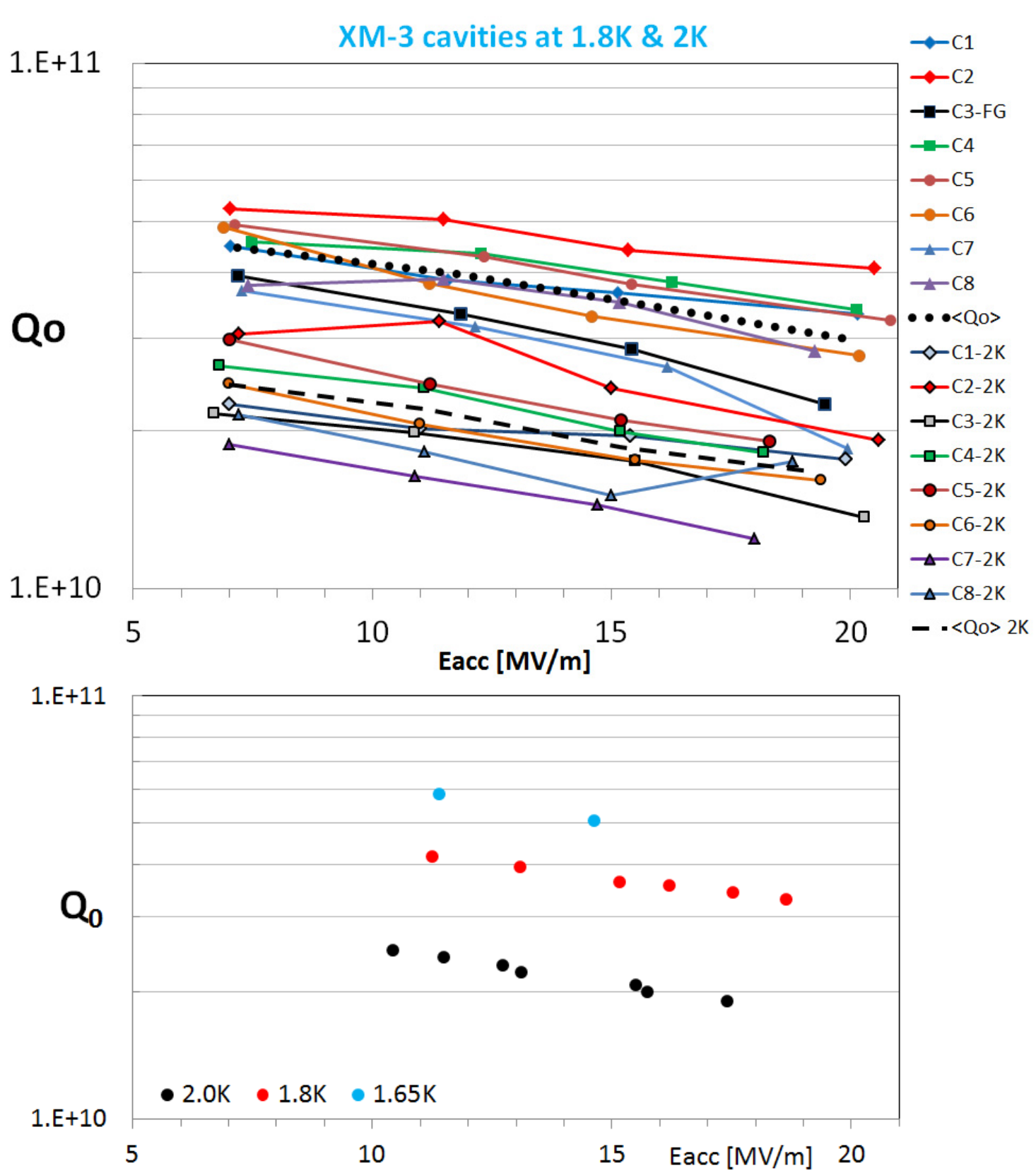


\section{CW Test Summary}

results and outlook

1. Some very encouraging results have been obtained at CMTB during continuous wave (CW) and long pulse (LP) tests of XFEL prototype cryomodules;

2. The high $\mathrm{Q}_{0}$ observed on large grain (LG) cavities might be an indication to pursue this approach when upgrading the front end cryomodules in the XFEL CW upgrade scenario;

3. RF stability compliant with the XFEL specifications $\left(10^{-4}\right)$ could be achieved in amplitude and phase at an optimal CW RF operation $Q_{L} \sim 4 \times 10^{7}$ with $16 . .20 \mathrm{MV} / \mathrm{m}$;

4. An amplitude and phase regulation of $\mathrm{dA} / \mathrm{A}=0.019 \%$ and $\mathrm{dP}=0.014^{\circ}$ respectively was achieved for a maximum gradient of $23.5 \mathrm{MV} / \mathrm{m}$ in $\mathrm{CW}$ mode;

5. Fast cooldown (FCD) increases $\mathrm{Q}_{0}$ by $45 \%$ at $1.8 \mathrm{~K}$ and $33 \%$ at $2 \mathrm{~K}$ : magnetic flux expulsion for FCD takes place;

6. With the next 2 cryomodules to be investigated in CW mode (XM46.1 and XM50.1), we will see how these results translate to series XFEL cryomodules;

7. More work is required on the LLRF system, to improve the robustness of the piezo feedback and automate the optimization of ANC parameters (frequency detection, learning rate...), a more sophisticated controller (MIMO-based) is in preparation. 
Conclusion 
1. Continuous Wave (CW) mode is the origin of the SRF accelerator technology. European XFEL project was based on the Linear Collider (LC) technology (TESLA) operating in the pulsed RF power mode $(10 \mathrm{~Hz} / 650 \mu$ s beam pulse). Many FEL user experiments will get an advantage (or become possible) with $\mathrm{CW}$ mode operation;

2. European XFEL SRF accelerator recently reached its project goal of $17.5 \mathrm{GeV}$ electron beam energy. Possible CW mode linac operation scenario with 17 modified injector section cryo-modules (CM) may reach $\sim 50 \%$ of that energy with $25 \mu \mathrm{A}(100 \mathrm{pC}$ and $250 \mathrm{kHz}$ ) CW beam in European XFEL. A Long Pulse (LP) mode (duty factor < 100\%) may provide even higher beam energies and still long enough FEL radiation pulses;

3. The SLAC LCLS-II project progressing to CW mode SRF linac based XFEL presents a few changes and optimizations of LC TESLA/E-XFEL technology for CW mode;

4. Some very encouraging results have been obtained at DESY on Cryo Module Test Bench (CMTB) during CW/LP tests of XFEL prototype CMs. The possibility to run an E-XFEL accelerating module in CW/LP mode was clearly shown together with reaching higher unloaded $\mathrm{Q}$-factor $\left(\mathrm{Q}_{0}\right)$ of the cavities in the $\mathrm{CM}$. 


\section{Acknowledgements}

We want to express our gratitude to all Colleagues contributing to and supporting the experiments and R\&D programs towards CW/LP SRF cavities operation modes:

DESY: V.Ayvazyan, J.Branlard, A.Bellandi, R.Brinkmann, M.Ebert, J.Eschke, A.Gössel, F.Mittag, W.Merz, W.-D.Möller, C.Müller, R.Onken, K.Przygoda, D.Reschke, R.Rybaniec, I.Sandvoss, H.Schlarb, A.Sulimov, E.Vogel, H.Weise...

TUL: $\quad$ W.Cichalewski, A.Piotrowski 
Thank you 


\section{Contact}

\section{DESY. Deutsches Denis Kostin}

Elektronen-Synchrotron

MSL

denis.kostin@desy.de

www.desy.de +49(40)8998-4585 